\title{
A AGRICULTURA FAMILIAR NO CONTEXTO DO AGRONEGÓCIO NO MUNICÍPIO DE CANGUÇU, ESTADO DO RIO GRANDE DO SUL, BRASIL
}

\author{
Jussara Mantelli ${ }^{1}$ \\ Éder Jardel da Silva Dutra² \\ Queli Rejane da Silva Konzgen ${ }^{3}$
}

Resumo: $O$ artigo trata da dicotomia entre agricultura familiar e agronegócio, mostrando a realidade do espaço agrário do município de Canguçu/RS. Para alcançar o entendimento desta questão foram analisados dados secundários e feitas observações diretas no campo, demonstrando que a presença do agronegócio se mescla com a diversificada produção orgânica em bases produtivas diferenciadas. Neste contexto, destacam-se as perspectivas e nuances da agricultura no que tange aos principais produtos agrícolas como o tabaco e a soja, que atingem a maior expressão em área no município, sem desconsiderar a produção orgânica que vem adquirindo importância não só na produção e comercialização, mas nas formas de organização dos produtores em associações.

Palavras-chave: Agricultura familiar. Agronegócio. Modernização agrícola. Município de Canguçu/RS.

\section{THE FAMILY FARMING IN THE CONTEXT OF AGRIBUSINESS IN THE MUNICIPALITY OF CANGUÇU, STATE OF RIO GRANDE DO SUL, BRAZIL}

\begin{abstract}
The article is about the dichotomy between family farming and agribusiness, showing the reality of the agrarian space of the municipality of Canguçu/Rio Grande do Sul. To achieve the understanding of this issue, secondary data were analyzed and direct observations were made in the countryside, demonstrating that the agribusiness presence mixes with the diversified organic production in differentiated productive bases. In this context, are highlighted the perspectives and nuances of agriculture, in reference of the main agricultural products, such as tobacco and soybeans, that reach the largest expression in municipality area, without neglecting the organic production, which is becoming important, not only in production and commercialization, but in ways of organization of the associated producers.
\end{abstract}

Keywords: Family farming. Agribusiness. Agricultural modernization. Municipality of Canguçu/RS.

\section{LA AGRICULTURA FAMILIAR EN EL CONTEXTO DEL AGRONEGOCIO EN EL MUNICIPIO DE CANGUÇU, ESTADO DEL RÍO GRANDE DEL SUR, BRASIL}

Resumen: El artículo trata de la dicotomía entre agricultura familiar y agronegócio, que muestra la realidad del espacio agrario del municipio de Canguçu/RS. Para lograr la comprensión de esta cuestión se analizaron datos secundarios y observaciones directas realizadas en el campo, lo que demuestra que la presencia del agronegocio se mezcla con la diversificada producción orgánica en bases productivas diferenciadas. En este contexto se destacan las perspectivas y matices de la agricultura, en lo que se refiere a los principales productos agrícolas como el

\footnotetext{
${ }^{1}$ Universidade Federal do Rio Grande, Instituto de Ciências Humanas e da Informação, Rio Grande, Brasil, jussaramantelli@furg.br, https://orcid.org/0000-0002-5252-4418

2 Universidade Federal do Rio Grande, Instituto de Ciências Humanas e da Informação, Rio Grande, Brasil, dutraeder1981@gmail.com, https://orcid.org/0000-0002-9149-5242

${ }_{3}^{3}$ Universidade Federal do Rio Grande, Instituto de Ciências Humanas e da Informação, Rio Grande, Brasil, queliufpel@gmail.com, https://orcid.org/0000-0002-4634-9182
} 
tabaco y la soja, que alcanzan la mayor expresión en área en el município, sin dejar de lado una producción orgánica, que está ganando importancia no sólo en la producción y comercialización, sino en las formas de organización de los productores en asociaciones.

Palabras clave: Agricultura familiar. Agronegocio. Modernización agrícola. Municipio de Canguçu/RS.

\section{Introdução}

A elaboração deste estudo pressupõe uma revisão teórica referente à temática da agricultura familiar e do agronegócio, além da coleta de dados secundários e de observações diretas e registros fotográficos no campo para validar os pressupostos teóricos, como referidos na metodologia apresentada.

Desde a década de cinquenta, o processo de modernização da agricultura brasileira vem atribuindo aspectos intrínsecos ao espaço agrário, de acordo com as características e especificidades locais. Este artigo trata da inserção da agricultura familiar ${ }^{4}$ no contexto do agronegócio 5 , tomando-se como referência o município de Canguçu, no estado do Rio Grande do Sul. Objetivamos verificar a inserção da agricultura familiar em cadeias produtivas globais, destacando as duas produções de maior expressão no município: o tabaco e a soja. Estas se consolidam em especial nos últimos 15 anos, como consequência advinda dos processos de modernização agrícola, e são significativas e impactantes quando observadas no universo da agricultura familiar.

Além da produção de tabaco e de soja, evidenciamos, no que se refere à organização da produção, a considerável diversidade do cultivo de pêssego direcionado para as indústrias conserveiras instaladas nos municípios vizinhos Pelotas e Morro Redondo; também a bacia leiteira que abastece as indústrias locais e regionais localizadas nos municípios de Capão do Leão e São Lourenço do Sul; e uma expressiva produção de alimentos orgânicos e agroecológicos que se enfatiza nos últimos dez anos, com a realização semanal das feiras públicas de comercialização. Destacam-se os produtores vinculados à União das Associações

\footnotetext{
${ }^{4}$ [...] a agricultura familiar vem ganhando legitimidade social, política e acadêmica no Brasil, passando a ser utilizada com mais frequência nos discursos dos movimentos sociais rurais, pelos órgãos governamentais e por segmentos do pensamento acadêmico, especialmente pelos estudiosos das ciências sociais que se ocupam da agricultura e do mundo rural (SCHNEIDER, 2003, p. 99).

5 De acuerdo a la FAO los agronegocios son: (...) la expansión de los negocios del sector agropecuario y rural y de sus cadenas, a partir de relaciones que involucran estructuras contractuales, alianzas o associaciones ejecutadas principalmente por el sector privado a partir de los produtores de del sector agropecuario, sostenibles a largo plazo, que involucran, además de um conjunto asociado de agricultores, a diversos agentes exógenos o de las cadenas agroindustriales y que podrían contar o no, con el apoyo de las políticas públicas (LÓPEZ, 2008, p. 121).
} 
Comunitárias do Interior de Canguçu (UNAIC) e à Associação Regional dos Produtores Agroecologistas da Região Sul (ARPA-SUL).

A diversidade na produção não é novidade na agricultura familiar. Wanderley (1999, p. 25), ao destacar Lamarche (1993), corrobora que: "[...] a agricultura familiar não é um elemento da diversidade, mas contém nela mesma toda a diversidade de elementos e atores".

As famílias que direcionam sua produção aos mercados do agronegócio, em especial da soja e do fumo, apresentam baixo grau de diversificação produtiva. No contexto da soja, é importante salientar que nem todos os produtores são familiares, pois começam a se consolidar grupos de investidores locais, normalmente comerciantes capitalizados que compram ou arrendam terras, em muitos casos de famílias que migraram para as cidades. Nos lugares mais distantes da área urbana, as terras possuem menor valor comercial, e é onde ocorre a expansão da soja sobre os espaços outrora reservados à pecuária de corte. Ainda, percebe-se que a soja avança em propriedades familiares com áreas entre cinco e vinte hectares, basicamente produtoras de tabaco. Nesses locais, a área não utilizada para 0 tabaco é arrendada, e o plantio de soja é feito em regime de parceria, com diferentes percentuais do resultado da produção para o proprietário e para o trabalhador, a partir de negociações prévias.

Em contraponto ao modelo de agronegócio, as famílias de agricultores envolvidas com a produção de orgânicos e agroecológicos exibem elevado grau de diversificação. Alguns desses agricultores produzem também sementes crioulas de uma variada gama de produtos (milho, feijão, batata, arroz, ervilha, abóbora, melão, porongo, entre outros) e são participantes de feiras e eventos em nível estadual para expor os resultados da produção.

A dicotomia entre uma agricultura familiar produtora de commodities (soja e fumo) está estabelecida com aqueles produtores que direcionam sua produção para produtos de base alimentícia, garantindo a soberania alimentar do município e até mesmo de municípios vizinhos, caso de Pelotas, onde são realizadas feiras semanais. Ressaltamos que essa é uma produção sem utilização de agrotóxicos, o que garante um processo solidário, em que a produção do alimento não é apenas uma tarefa, mas o labor diário de um saber-fazer, estruturada a partir da tradição arraigada no universo da produção familiar.

Com vistas a entender essa dicotomia, este artigo evidencia a agricultura familiar no município de Canguçu, enfatizando as atividades vinculadas ao chamado 
agronegócio e suas consequências na realidade local. Para tal, utilizamos a abordagem qualitativa, a qual, em conformidade com Rodrigues (2007, p. 38-39), "[...] é a pesquisa que predominante pondera, analisa e interpreta dados relativos à natureza dos fenômenos, sem que os aspectos quantitativos sejam sua preocupação precípua [...]".

Todavia, cabe ressaltar que, segundo Chizzotti (1995), a pesquisa qualitativa não descarta o uso de dados quantitativos, essencialmente no estudo exploratório ou nas etapas em que os dados podem apresentar uma relação entre fenômenos particulares. Quanto à análise qualitativa de dados, Apolinário (2006, p. 160) aborda que:

[...] o processo de análise é sistemático e compreensivo, mas não é rígido: diferentemente da análise quantitativa, não há testes de significância estatística que possam determinar que a análise chegou ao fim. Em pesquisas qualitativas, a análise chega ao fim com o surgimento de padrões e regularidades que possam ser objeto de atribuição de significados pelo pesquisador.

A investigação insere-se na compreensão de um estudo de caso, por se tratar do município de Canguçu, e como menciona Chizzotti (1995, p. 102):

Uma caracterização abrangente para designar uma diversidade de pesquisas que coletam e registram dados de um caso particular ou de vários casos a fim de organizar um relatório ordenado e crítico de uma experiência ou avaliá-la analiticamente, objetivando tomar decisões a seu respeito ou propor uma ação transformadora.

Quanto à metodologia para a elaboração deste estudo, na primeira etapa foi realizada uma revisão teórica sobre os temas agricultura familiar, agronegócio e modernização da agricultura. Na segunda etapa, foram coletados dados em fontes secundárias, principalmente do Instituto Brasileiro de Geografia e Estatística (IBGE), do Sistema IBGE de Recuperação Automática (SIDRA), do Instituto Nacional de Colonização e Reforma Agrária (INCRA), da Prefeitura Municipal de Canguçu, ou em entidades de classe de domínio público como o Sindicato Interestadual da Indústria do Tabaco (SindiTabaco) e a Associação dos Fumicultores do Brasil (AFUBRA). Os dados em questão são referentes à área de estudo sobre população, estrutura fundiária, cultivo do tabaco e da soja, entre outros. Na terceira etapa foram realizadas observações de campo que resultou em uma maior entendimento das questões mais pontuais e permitiu realizar um levantamento fotográfico das culturas agrícolas predominantes no município, com o objetivo de ilustrar a realidade local. 
Canguçu está localizado na porção sul do estado, na região fisiográfica caracterizada como Serra do Sudeste, no Escudo Cristalino Sul-rio-grandense, como mostra a Figura 1.

Figura 1 - Mapa de localização do município de Canguçu no Rio Grande do Sul

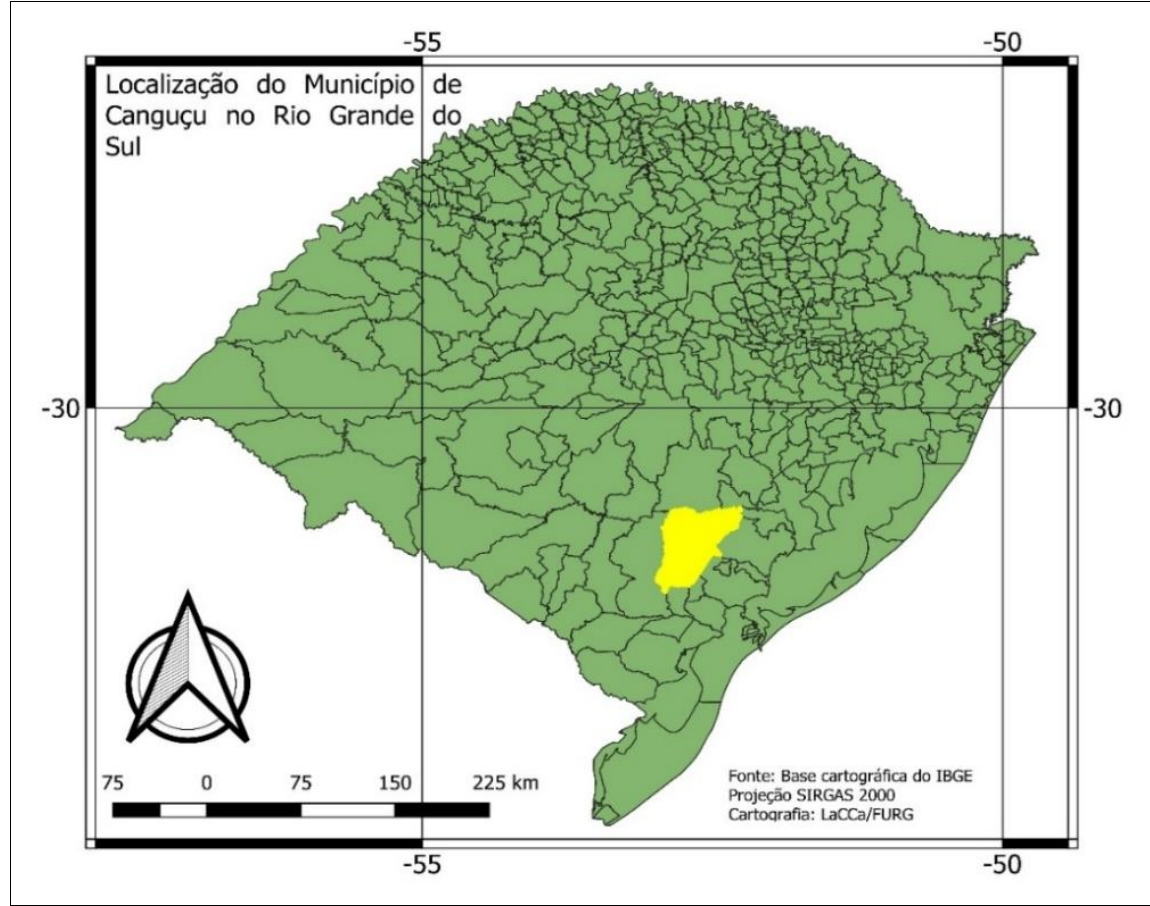

Fonte: Laboratório de Climatologia e Cartografia (LaCCa/FURG), 2018.

Pela importância da agricultura para a área de estudo, torna-se relevante que estabeleçamos as correlações com a concepção de agricultura familiar retomando as bases teóricas que a conceituam, mostrando as particularidades da inserção de famílias rurais no universo do agronegócio. Com o objetivo de fazer um recorte de temas complexos para os quais não há uma definição única, trazemos as principais referências acerca da temática.

\section{Agricultura familiar e seus matizes: as origens do conceito}

Ao compreendermos que a agricultura familiar é a categoria de análise adequada para darmos conta da realidade do município de Canguçu, não estamos desconsiderando as singularidades que envolvem o campesinato, sua importância histórica, bem como a existência dessas características na realidade em estudo. Nesse sentido, destaca-se Oliveira (1986, p. 6), ao dizer que: 
Procurando entender essas e outras transformações que o campo vem sofrendo, surgem inúmeras correntes de interpretação dessas realidades. De uma maneira geral, poderíamos dizer que os estudiosos da questão agrária concordam, tanto para o campo como para a cidade, com o processo de generalização progressiva por todos os ramos e setores da produção, o assalariamento, relação de produção específica do modo capitalista de produção.

Feliciano (2006, p. 21) com base em Oliveira (1995), ao estudar as correntes teóricas no universo da agricultura brasileira, especialmente as que envolvem agricultura familiar e campesinato, destaca que o avanço das relações capitalistas de produção na agricultura é algo inconteste, especialmente no universo da agricultura familiar, tomada aqui como categoria de análise. $\mathrm{O}$ autor esclarece que as principais correntes teóricas que permeiam o debate sobre o modo capitalista de produção e a agricultura brasileira são: a) a teoria clássica que defende uma generalização inevitável das relações capitalistas do campo, havendo em um determinado momento uma divergência com relação aos caminhos dessa generalização; b) a tese sobre a existência das relações feudais de produção na agricultura; e c) uma terceira corrente que tem como princípio o entendimento da criação e recriação do campesinato e do latifúndio no campo brasileiro.

Heynig (1982, p. 128) acresce: "Mientras la empresa capitalista produce valores de cambio, el campesino produce valores de uso, principalmente para el autoconsumo". O entendimento dessas questões é um ponto relevante, uma vez que a agricultura familiar envolvida com a produção de tabaco ou soja destina-se apenas às demandas de mercado, e todas as famílias envolvidas nessas produções visam à obtenção do lucro. Feliciano (2006, p. 26) apud Oliveira (1995) destaca que:

Uma discussão que atualmente aquece os debates dos estudiosos da questão agrária, tanto no meio acadêmico como no meio político, ou de ambos simultaneamente, remete-se à intepretação de duas visões de mundo diferenciadas: a agricultura familiar versus a agricultura camponesa.

Lênin, na obra O desenvolvimento do capitalismo na Rússia: o processo de formação do mercado interno para a grande indústria (1985), fornece subsídios para atender a chamada desintegração do campesinato:

O conjunto de contradições existentes no interior do campesinato constitui o que denominamos desintegração do campesinato. Empregando a palavra descamponização, os próprios camponeses fornecem uma definição extremamente precisa e relevante desse processo, que redunda na destruição radical do antigo campesinato patriarcal e na criação de novos tipos de população rural (LÊNIN, 1985, p.113). 
Kautsky (1980, p. 112) reflete que: "[...] quanto mais o capitalismo progride na agricultura, acentua a diferença qualitativa entre a técnica da grande e da pequena exploração." Abramovay (2007, p. 188) explica:

[...] Aqui, da mesma forma que nos Estados Unidos - e, de maneira geral, em todo o mundo capitalista avançado -, foi a agricultura familiar que, sobretudo após a Segunda Guerra Mundial, responsabilizou-se não só por assegurar um consumo alimentar mais do que suficiente aos europeus, mas por garantir ao Continente o lugar em 1988 de segundo exportador mundial de produtos agrícolas, logo após os Estados Unidos. Esse desempenho só foi possível em virtude de um conjunto tão grande e profundo de transformações na agricultura familiar que faz dela não a resistência de formas sociais anteriores, mas, ao contrário, uma realidade econômica e social absolutamente inédita que, com sua base ancestral, guarda semelhança cada vez mais pálida.

Almeida (2009, p. 17-18) avalia que:

Nas ciências sociais, o tema relacionado à agricultura e seus conceitos começa a apresentar interesse no Brasil nos últimos anos. Até então, os principais trabalhos realizados sobre a agricultura do país eram limitados a processos internos e à dinâmica da agricultura "moderna", com pouca ênfase nas formas não dominantes, extrapolando os esquemas tradicionais.

No campo, as organizações sociais, especialmente aquelas vinculadas à chamada "pequena agricultura", ganharam forças para pressionar o governo brasileiro a ter um olhar diferenciado. Como resposta à demanda dos coletivos sociais, basicamente de pequenos agricultores, o governo brasileiro criou, no governo de Itamar Franco (1992-1995), o chamado Programa de Valorização da Pequena Produção (PROVAP), posteriormente transformado no Programa Nacional de Fortalecimento da Agricultura familiar (PRONAF). Schneider et al. (2004, p. 22) expõem que:

É preciso lembrar que, no contexto do início da década de 1990, a agricultura brasileira, e particularmente a da região Meridional do Brasil, estava fortemente afetada pelo processo de abertura comercial e de desregulamentação dos mercados, fatores que a submetiam a uma concorrência intensa com os países do MERCOSUL. Em vista das sucessivas dificuldades decorrentes da crise da segunda metade dos anos 80 , particularmente no que se refere à disponibilidade de crédito e da queda da renda, os agricultores familiares da região Sul do Brasil, e em menor medida os agricultores da região Nordeste (sobretudo produtores de algodão), encontravam-se debilitados diante da nova conjuntura econômica e comercial.

Schneider et al. (2004, p. 23-24) afirmam que "a partir de 1995, já no governo Fernando Henrique Cardoso, o PROVAP foi totalmente reformulado, tanto 
em termos de concepção como em sua área de abrangência. Essas modificações deram origem ao PRONAF, em 1996 [...]". A partir desse período, o referido programa consolidou-se como a principal política pública de valorização da agricultura familiar, garantidora de sua viabilidade social e econômica em novas bases, calcada, sobretudo no crédito subsidiado.

É no ponto de intersecção da agricultura familiar-agronegócio que reside nosso interesse ao buscarmos o entendimento das dinâmicas que regem a agricultura familiar e seu ingresso na modernização agrícola, sendo inserida pela dinâmica das cadeias produtivas globalizadas. Interessa-nos o entendimento da agricultura familiar e seu ingresso nas cadeias produtivas globais, como a produção de tabaco e de soja por agricultores familiares do município de Canguçu.

\section{A modernização do campo e a agricultura familiar}

O padrão moderno de desenvolvimento é algo controverso, pois procura estender as influências de maneira homogênea, não respeitando as particularidades locais. O atual padrão de desenvolvimento implantado no campo brasileiro se intensifica após a década de 1970. Entre as muitas questões, salientam-se a dependência do agricultor em relação às tecnologias externas e a adoção de variedades e cultivares que necessitam de pacotes tecnológicos fechados.

Featherstone (1995, p. 17) ressalta que a "modernização é um termo usado habitualmente na sociologia do desenvolvimento para indicar os efeitos do desenvolvimento econômico sobre estruturas sociais e valores tradicionais [...]". A modernização como processo intensifica a interação entre a cidade e o campo e permite a colocação de regiões outrora periféricas no circuito produtivo moderno. Esse processo não é homogêneo; ao contrário, possui nuances e é por si só excludente de regiões, de lugares e de pessoas. Almeida (2009, p. 151) menciona:

\footnotetext{
A atual situação da agricultura no sul do Brasil não permite, ainda, dar resposta a essas questões. O que se sabe é que essas experiências servem para alguns grupos e indivíduos resistirem em condições difíceis. Os agricultores que buscam experimentar esses sistemas mais autônomos estão de fato na busca de alguma coisa portadora de mais solidariedade e com a qual se possam identificar, ou seja, de um sistema que possa responder as suas tentativas pessoais de reencontrar a 'coerência'do modelo camponês (MULLER, 1987), uma coerência que se perdeu ao longo do processo [...].
}

Assim, Suzuki (2009, p. 242) com base em Graziano da Silva (1982, p. 46) aprofunda a discussão salientando que: 
[...] é apenas após haver consolidado a hegemonia do capital industrial com a industrialização pesada que se deslancha o processo de "modernização" da agricultura brasileira. [...] é por força do próprio processo de industrialização do País que a agricultura deixa de ser um setor "quase auto-suficiente" da economia para se tornar integrante de um conjunto maior de atividades inter-relacionadas. Em poucas palavras, no processo de desenvolvimento capitalista brasileiro de pós-guerra, a agricultura se converteu gradativamente num setor subordinado à indústria e por ela é transformada.

Suzuki (2009, p. 242) postula algumas situações para o entendimento da modernização como um processo ao longo da história. O autor demostra "a compreensão de que a modernização da agricultura brasileira só tenha iniciado em meados do século $X X$, no pós-guerra, é um grande equívoco historiográfico. Para nós, a modernização, no Brasil, atinge, no mesmo período, tanto o campo, como a cidade". Nesta linha de pensamento, a compreensão de modernização é ampla, com avanços no espaço e no tempo. E o processo busca:

[...] compreender a modernização da agricultura como um movimento de reelaboração da base técnica, bem como das relações de submissão do trabalho ao longo da história do homem. A modernização da agricultura vem acontecendo a partir do momento em que o homem começou a lidar com a prática do cultivo e dos sistemas criatórios (SUZUKI, 2009, p. 242).

$\mathrm{Na}$ realidade de Canguçu identificamos que os processos modernizantes se consolidaram nos anos posteriores a 1980, com a produção de tabaco e com a soja a partir do início do século corrente, quando ocorre um aumento considerável na área plantada. Todavia, foram nos últimos 15 anos que se estabeleceram os processos de modernização e adesão dos produtores de soja aos pacotes tecnológicos e na produção de tabaco e introduzidas técnicas modernas de produção, especialmente no cultivo e na secagem. Destacamos um variado grupo de empresas nacionais e internacionais que organizam a produção e a comercialização de produtos oriundos do tabaco, resultando muitas vezes na perda de autonomia do trabalho e da produção dos agricultores familiares.

$\mathrm{Na}$ produção de tabaco, estão sendo gradativamente introduzidas novas variedades como a produção de tabaco orgânico, visando atender nichos específicos de mercado. Fontoura (2009, p. 282) já referenciava esse argumento, colocando novos elementos para o entendimento do tema: "O campo passa a produzir um produto específico para um segmento específico de consumidor urbano, que se relacionam com seu imaginário, valores e até mesmo fetiches".

Em Canguçu, a produção de tabaco é organizada a partir do sistema integrado de produção e levada adiante por grupos empresariais como: a) Alliance 
One Internacional; b) Philip Morris International Brazil; c) China Brasil Tabacos Exportadora S.A.; d) Souza Cruz; e outros grupos empresariais com derivações nacionais e internacionais, que articulam as fases da produção e a distribuição do produto final (cigarros, charutos) em nível global. Como bem demonstra Resende (1997, p. 31): “A mercadoria, por vocação, é sedenta por espaço”. Portanto, buscamos visualizar a agricultura familiar imersa no universo do agronegócio, basicamente com a cultura do tabaco e da soja, mas também explicitamos algumas alternativas ao modelo exposto, como a agricultura orgânica e agroecológica e a produção de sementes crioulas emergindo em âmbito municipal.

\section{Agricultura familiar no município de Canguçu ou agronegócio?}

A agricultura familiar no contexto do denominado agronegócio é algo complexo e de muitas nuances. Para consolidar a importância desta dicotomia, destacamos Muller (1989, p. 34), que colabora no entendimento do avanço da modernização agrícola e dos processos de integração agricultura-indústria:

Com a integração indústria e agricultura no período 1960-80, deparamo-nos com empresas e grupos econômicos que influenciam poderosamente a dinâmica das atividades agrárias, com profundas repercussões em suas estruturas. Mas na própria agricultura surgem empresas e grupos econômicos, que com suas congêneres industriais, fazem parte do poder econômico com interesses em atividades agrárias.

Por sua vez, Coradini e Fredericq (1982, p. 93) mostram que "a produção agropecuária, hoje em dia, não é mais um setor isolado das demais atividades sócio-econômicas". Silva (1999, p. 137) traz:

[...] Em nível interno da unidade produtiva, a variável tecnológica encontra-se estreitamente associada com a disponibilidade de recursos físicos e financeiros, com o processo de produção e de trabalho, com a divisão interna do trabalho entre os membros da família ou mão-de-obra eventualmente contratada, etc.

Sacco dos Anjos e Caldas (2009, p. 159) ratificam aspectos inerentes à relação das famílias integradas aos Complexos Agroindustriais (CAls) e ligados à produção de tabaco:

[...] a relação das famílias com as empresas é regida por contratos de integração vertical que, se por um lado, asseguram a compra antecipada da produção, por outro, obrigam as primeiras à adoção de um pacote tecnológico: adubos, agrotóxicos e serviços (assistência técnica) que serão descontados ao final da safra. Mas os produtores são responsáveis pela secagem do fumo colhido a campo [...] sendo essa uma etapa das mais complexas face aos riscos que envolvem a qualidade da produção, a insalubridade da operação e a extensão das jornadas de trabalho. 
Como afirma Fontoura (2009, p. 276): "O modelo imposto refere-se à integração de capitais urbanos ao campo [...] a novidade é que vem respaldada pelo amplo apoio creditício, da assistência técnica, da infraestrutura e pela legitimidade do Estado, através da ideologia do desenvolvimento". Alves et al. (2005, p. 153) pontuam que:

\begin{abstract}
A integração, nascida da forma empresarial, busca seu desenvolvimento em regiões de predomínio da agricultura familiar [...], no entanto, esta inserção vem se modificando, porque as imposições tecnológicas chegaram a tal ponto que não é mais possível ser suportado pela agricultura familiar, aos poucos esta vai cedendo espaço ao modo empresarial de produção.
\end{abstract}

Flach (2012, p. 266) evidencia acerca da penetração do capitalismo na agricultura: "O capital se apoderou da agricultura através da inserção e submissão do agricultor ao mercado [...]".

A questão sensível é a busca do entendimento das formas que a agricultura familiar encontra para sua reprodução social ${ }^{6}$, acabando por aliar-se em muitos casos ao agronegócio com produtos específicos, casos da soja e do tabaco. É um novo tipo de relações. Silva (1999, p. 237) dá conta dessas particularidades: "[...] E, em nível das relações externas, com o grau de mercantilização da produção e articulação com os sistemas de comercialização e financiamento". Martins (1981, p. 152) enfatiza que: "[...] A tendência do capital é a de tomar conta progressivamente de todos os ramos e setores da produção, no campo e na cidade, na agricultura e na indústria".

A expressão pode ter seu entendimento nas palavras de Fernandes e Welch (2008, p. 49), como se vê: "[...] No sistema agrícola do agronegócio, a monocultura, o trabalho assalariado e a produção em larga escala são algumas das principais referências". Cleps Junior (2010, p. 40) explicita considerações que passam a entremear a realidade rural brasileira, especialmente do final da década de 1980 em diante, como segue:

O surgimento de novos termos como o agribusiness foi proposto pela primeira vez nos anos 1950 no Centro de Administração de Negócios (Graduate School of Business Administration, de Harvard) por dois autores norte-americanos, Jonh Davis e Roy Goldberg (A Concept of Agribusiness, 1957), para explicar o processo de subordinação e as relações da

\footnotetext{
${ }^{6}$ Almeida (1986, p. 67), com base em Fortes (1971, p. 87), salienta: A noção de reprodução social (de produção da sociedade) foi formulada em nível macro por Marx. Antropólogos enfatizaram que os átomos da reprodução são famílias. Fortes, em artigo de 1958, define reprodução social como o processo de "manter, repor e transmitir o capital social de geração para geração", sendo o grupo doméstico seu mecanismo central, o qual tem simultaneamente uma dinâmica interna e um "movimento governado por suas relações com o campo externo".
} 
agricultura com setores industriais e comerciais. O termo define-se como a soma total de todas as operações envolvidas na manufatura e na distribuição de suprimentos agrícolas; de operações de produção no campo, e de armazenamento, de processamento e de distribuição de produtos agrícolas, bem como itens produzidos.

O município de Canguçu, marcado historicamente pelo que denominamos de agricultura familiar de subsistência até o início dos anos 1980, passa nos últimos 20-30 anos para uma agricultura fundamentalmente comercial. Instala-se a dimensão da lógica capitalista, com aplicação maciça de capitais, em especial de grupos fumageiros nacionais e internacionais, propiciando e fazendo surgir uma realidade distinta daquela vigente outrora.

\section{Características e realidades do município de Canguçu: a produção agrícola moderna}

O município de Canguçu, ao longo de sua formação histórica, tem a trajetória vinculada ao que compreendemos como agricultura familiar. Sua população, reduções e incrementos têm grande relação com as mudanças ocorridas no interior das unidades familiares de produção. A Tabela 1 apresenta a população rural e urbana em Canguçu de 1920 até 2010, com a estimativa para 2018.

Tabela 1 - População rural e urbana em Canguçu (1920-2010)

\begin{tabular}{cccccc}
\hline Ano & $\begin{array}{c}\text { População } \\
\text { Rural }\end{array}$ & $\%$ & $\begin{array}{c}\text { População } \\
\text { Urbana }\end{array}$ & $\%$ & $\begin{array}{c}\text { População } \\
\text { total }\end{array}$ \\
\hline $\mathbf{1 9 2 0}$ & 25.900 & 95,95 & 1.100 & 4,05 & 27.000 \\
$\mathbf{1 9 4 0}$ & 47.177 & 93.29 & 2.895 & 6,71 & 50.162 \\
$\mathbf{1 9 5 0}$ & 55.769 & 95,81 & 2.438 & 4,19 & 58.207 \\
$\mathbf{1 9 6 0}$ & 54.281 & 94,59 & 3.257 & 5,41 & 57.538 \\
$\mathbf{1 9 7 0}$ & 57.256 & 91,68 & 5.195 & 8,32 & 62.451 \\
$\mathbf{1 9 8 0}$ & 46.947 & 84,09 & 8.878 & 15,91 & 55.825 \\
$\mathbf{1 9 9 1}$ & 36.556 & 72,57 & 13.811 & 27,43 & 50.367 \\
$\mathbf{1 9 9 6}$ & 34.608 & 69,15 & 15.437 & 30,85 & 50.045 \\
$\mathbf{2 0 0 0}$ & 33.742 & 65,58 & 17.685 & 34,41 & 51.447 \\
$\mathbf{2 0 0 7}$ & 33.443 & 62,91 & 18.712 & 37,09 & 53.155 \\
$\mathbf{2 0 1 0}$ & 33.565 & 63,02 & 19.694 & 36,98 & 53.259 \\
$\mathbf{2 0 1 8}$ & & & & & 55.871 \\
\hline
\end{tabular}

Fonte: IBGE, 2018.

Os dados revelam uma tendência brasileira de redução do número da população residente no meio rural e o constante incremento da população urbana, com algumas particularidades temporais. O intervalo compreendido entre os anos de 1970 e 2000 foi o período em que houve redução considerável da população rural,

7 População total estimada para 2018. 
como no caso estudado, em que se passou de 57.256 em 1970 para 33.742 habitantes em 2000. Parte dessa população migrante rural buscou outras possibilidades em cidades próximas, como Pelotas ou até mesmo na zona urbana de Canguçu, a qual entre 1970 e 2000 passou de 5.195 para 17.685 habitantes, tendência que se consolida e chega a 19.964 habitantes urbanos em 2010. Com a modernização implantada no campo, especialmente com o cultivo da soja e a consequente mecanização, foi sendo liberado gradualmente um grande contingente de trabalhadores rurais. Todavia, atividades como a fumicultura ou a produção de alimentos orgânicos e agroecológicos necessitam maior demanda por trabalhadores, o que explica em parte a estagnação da população rural ou leve acréscimo nos últimos dez anos.

É importante destacar a estrutura fundiária de Canguçu, marcada basicamente por imóveis caracterizados por propriedades destinadas ao uso pela agricultura familiar. É o que apresenta a Tabela 2, com os dados referentes à estrutura fundiária do município de Canguçu em 2012.

Tabela 2 - Estrutura fundiária do município de Canguçu (2012)

\begin{tabular}{|c|c|c|c|c|}
\hline $\begin{array}{c}\text { Grupos de Área } \\
\text { (ha) }\end{array}$ & $\begin{array}{c}\text { № de } \\
\text { Imóveis }\end{array}$ & $\begin{array}{l}\text { \% do № de } \\
\text { Imóveis }\end{array}$ & $\begin{array}{l}\text { Área total } \\
\text { dos } \\
\text { imóveis }\end{array}$ & $\begin{array}{l}\% \text { total dos } \\
\text { imóveis }\end{array}$ \\
\hline 0 a 10 & 6.103 & 46,19 & $29.776,3$ & 9,41 \\
\hline 10,1 a 20 & 3.418 & 25,87 & $50.483,5$ & 15,95 \\
\hline 20,1 a 50 & 2.692 & 20,37 & $81.901,8$ & 25,88 \\
\hline 50,1 a 100 & 557 & 4,22 & $38.008,2$ & 12,00 \\
\hline 100,1 a 200 & 261 & 1,97 & $36.080,8$ & 11,40 \\
\hline 200,1 a 500 & 133 & 1,01 & $38.745,5$ & 12,24 \\
\hline 500,1 a 1.000 & 37 & 0,29 & $25.922,2$ & 8,19 \\
\hline $1.000,1$ a 1.500 & 6 & 0,04 & $7.543,5$ & 2,38 \\
\hline $1.500,1$ a 2.000 & 2 & 0,02 & $3.378,4$ & 1,07 \\
\hline $2.000,1$ a 2.5000 & 2 & 0,02 & $4.674,6$ & 1,48 \\
\hline Total & 13.211 & 100 & $316.514,8$ & 100 \\
\hline
\end{tabular}

Dos 13.211 imóveis existentes no ano de 2012, 51,24\% possuíam menos de 50 hectares, e muitas dessas propriedades estão envolvidas com a cultura comercial do tabaco. O domínio das propriedades familiares, em especial com a produção do tabaco, é uma marca do município. Constitui-se uma situação ímpar, que tem relação com o aumento do plantio da soja, que passa a ser cultivada em larga 
escala após os anos 2000 , até mesmo em propriedades com áreas inferiores a dez hectares.

Nas localidades rurais onde está presente a cultura do tabaco, observa-se maior concentração populacional; todavia, nos locais onde predomina a soja há migração e intensificação do êxodo rural. As localidades afastadas da sede onde predomina a cultura da soja são as que apresentam as maiores proporções de esvaziamento populacional de jovens que migram para as áreas urbanas e também estão marcadas pelo aumento médio das áreas das propriedades.

Alteram-se as características dominantes da realidade do município com a relevância que assumem o tabaco e a soja. Nas localidades onde há o predomínio da soja, existem propriedades com áreas superiores a 500 hectares, que tradicionalmente eram utilizadas para a pecuária extensiva e nos últimos dez anos passam a ser substituídas pela sojicultura. Nessas áreas se percebe claramente a presença de residências abandonadas e os maiores índices de êxodo rural, com poucos jovens e uma população residente majoritariamente idosa. Outra situação visualizada diz respeito à mão de obra empregada, posto que as propriedades de tamanho médio e grande utilizam a mecanização, requerendo pouca mão de obra.

A fumicultura é a principal fonte geradora de renda na área de estudo, seguida pela produção de soja, pelos benefícios previdenciários, pela pecuária de leite e corte, além de outras atividades econômicas (leite, pêssego, milho e alimentos orgânicos). A fumicultura é a principal responsável pela geração de empregos e renda, com a aplicação intensiva da força de trabalho familiar e a existência de uma série de empresas instaladas no meio urbano para atender as demandas rurais.

A AFUBRA é o ponto de conexão dos produtores com as fumageiras. E a instalação de sua loja e escritório em Canguçu, em 2010, reflete a significância que a produção de tabaco tem em Canguçu e região, com aumento nas áreas plantadas e nas quantidades produzidas, constituindo-se um polo regional de produção fumageira. Nos anos 2013-2014 havia as seguintes empresas com atuação em Canguçu: a) Alliance One Internacional; b) ATC - Associated Tobacco Company; c) China Brasil Tabacos Exportadora S.A., d) CTA - Continental Tobaccos Alliance S/A; e) INTAB - Indústria de Tabacos e Agropecuária; f) JTI - Japan Tobacco Internacional; g) Philip Morris International Brazil; h) Premium Tabacos do Brasil; i) Souza Cruz; e, por fim, j) Universal Leaf Tabacos Ltda. Como expõem Maldonado, Almeida e Picciani (2017, p. 81): 
Com a centralização do capital no agronegócio, isto é, o surgimento de megaempresas advindas dos processos de fusões e aquisições, é cada vez mais recorrente a instalação das sedes corporativas das grandes firmas nas principais áreas metropolitanas, de onde controlam suas unidades produtivas e escritórios regionais dispersos pelas principais regiões produtivas.

Acerca da capilaridade territorial do agronegócio, Gonçalves (2012, p. 59) elucida: "As cadeias de produção dos agronegócios são a síntese de uma territorialidade integradora derivada do processo de desenvolvimento capitalista, [...]". Ainda evidencia Gonçalves (2012, p. 59), ao se referir às características dos agronegócios, que: "[...] a mais relevante é a complementariedade de várias zonas de produção, que permite superar as limitações das ofertas sazonais de produtos". No caso da produção de tabaco, existe uma diferença de época de plantio entre o estado do Rio Grande do Sul, que inicia nos meses de outubro, novembro e dezembro, com os estados do Paraná e Santa Catarina, cuja atividade de plantio se desenvolve a partir do mês de agosto.

Quando temos em conta os municípios com maior produção de tabaco em toneladas na safra 2017-2018, vemos que todos pertencem à região sul do Brasil, como destacado na Tabela 3.

Tabela 3 - Municípios com maior produção de tabaco no Brasil (Safra 20172018)

\begin{tabular}{|c|c|c|}
\hline Ordem & Municípios & Produção em Toneladas \\
\hline 10 & Canguçu/RS & 22.142 \\
\hline $2^{\circ}$ & Venâncio Aires/RS & 20.872 \\
\hline $3^{\circ}$ & São Lourenço do Sul/RS & 17.410 \\
\hline $4^{\circ}$ & Itaiópolis/SC & 16.728 \\
\hline 5은 & Canoinhas/SC & 15.945 \\
\hline $6^{\circ}$ & São João do Triunfo/PR & 14.729 \\
\hline 70 & Santa Cruz do Sul/RS & 13.990 \\
\hline $8^{\circ}$ & Candelária/RS & 13.971 \\
\hline 9은 & Santa Terezinha/SC & 13.762 \\
\hline $10^{\circ}$ & Camaquã/RS & 13.625 \\
\hline
\end{tabular}

Ao observamos os dados, verificamos que o município de Canguçu ocupa a posição de destaque entre os dez maiores produtores de tabaco do Brasil, juntamente com outros municípios do sul do estado do Rio Grande do Sul, os casos de São Lourenço do Sul e Camaquã. Podemos mencionar que a região sul do estado atualmente é um polo produtor da matéria-prima, em que pese o fato de o processamento de tabaco desenvolver-se na região de Santa Cruz do Sul. Existem 
tratativas por parte de alguns grupos empresariais com o governo municipal para a instalação de unidades de processamento de tabaco em Canguçu, e pelas informações que dispomos, o projeto está em estágio de negociações e possivelmente de eleição da área onde será realizado o futuro investimento.

Um dado importante corresponde à questão da dimensão das propriedades produtoras de tabaco no Sul do Brasil, como demonstrado na Tabela 4, com valores obtidos e estruturados pelo departamento de estatísticas do SindiTabaco. As informações são coletadas pelos instrutores em campo e posteriormente repassadas ao departamento responsável por sua análise.

Tabela 4 - Dimensão das propriedades e número de famílias produtoras de tabaco na região Sul do Brasil (Safra 2017-2018)

\begin{tabular}{ccc}
\hline Hectares (estrato) & Famílias Produtores & $\%$ \\
\hline Menos de 1 & 39.753 & 26,6 \\
1 a 10 & 53.776 & 36,0 \\
$\mathbf{1 1}$ a 20 & 36.026 & 24,1 \\
21 a 30 & 13.454 & 9,0 \\
31 a 50 & 5.051 & 3,4 \\
Mais de 50 & 1.290 & 0,9 \\
Total & 149.350 & 100,00 \\
\hline
\end{tabular}

Fonte: SindiTabaco, 2018.

A cultura do tabaco desenvolve-se fundamentalmente em pequenas propriedades, é o caso do estrato entre um e dez hectares concentrando $36 \%$ das propriedades e 53.776 famílias produtoras. Já o estrato inferior a um hectare concentra $26,6 \%$ das propriedades e um total de 39.753 famílias produtoras da região sul do Brasil. Isso nos possibilita dizer que a cultura do tabaco, em suas diferentes fases de produção até a venda para indústria, é desenvolvida em pequenas propriedades e levada adiante por membros do grupo familiar.

A Figura 2, referente à safra 2018-2019, mostra a vista parcial de propriedades rurais utilizadas para o cultivo de tabaco. Um fato importante está relacionado com a presença da mão de obra, basicamente da família e eventualmente contratação na modalidade diária ou por tarefa, principalmente para o plantio e colheita do tabaco na lavoura, atividades que requerem pessoas, uma vez que o trabalho se dá de forma manual. 
Figura 2 - Propriedades familiares com cultivo de tabaco safra 2018-2019

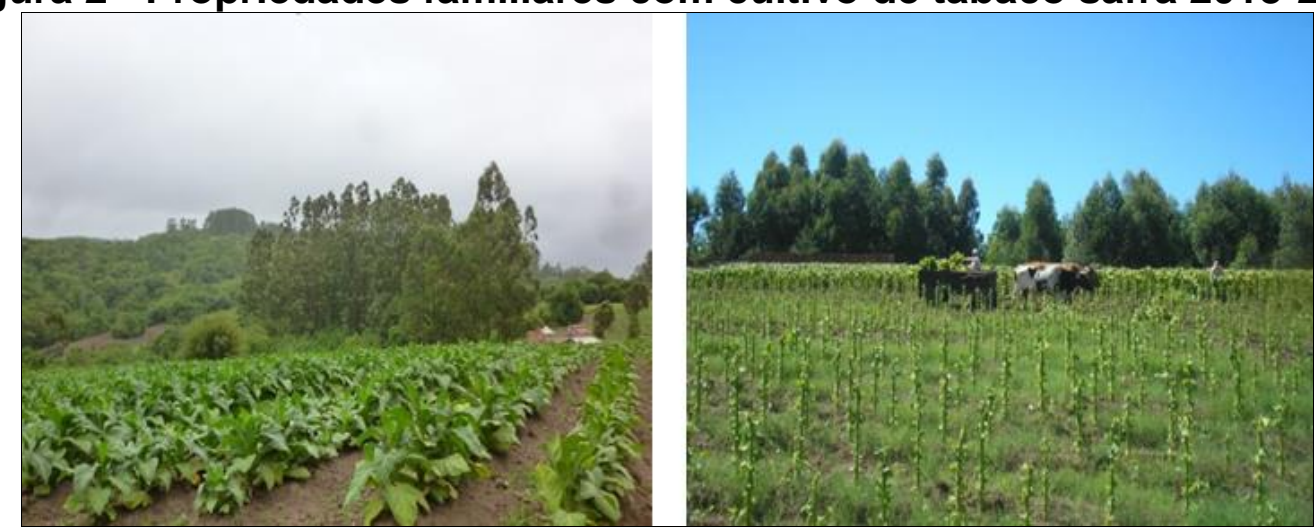

Fonte: Acervo dos autores, 2018.

A produção de tabaco ocorre em propriedades familiares e áreas que normalmente não se prestam a produções como soja ou milho. Usualmente, são cultivadas em áreas inferiores a cinco hectares e com aplicação de pacotes tecnológicos desenvolvidos pelas fumageiras. A Tabela 5 mostra que a cultura do tabaco é relevante uma vez que se desenvolve no universo da agricultura familiar.

Tabela 5 - Produção de tabaco no município de Canguçu - Área colhida e
\begin{tabular}{cccc} 
quantidade produzida (Safra 2007-2017) \\
\hline Ano & $\begin{array}{c}\text { Área Colhida } \\
\text { (Hectares) }\end{array}$ & $\begin{array}{c}\text { Quantidade Produzida } \\
\text { (T) }\end{array}$ \\
\hline $\mathbf{2 0 0 7}$ & 10.000 & 22.000 \\
$\mathbf{2 0 0 8}$ & 7.906 & 16.547 \\
$\mathbf{2 0 0 9}$ & 8.908 & 17.255 \\
$\mathbf{2 0 1 0}$ & 8.908 & 13.362 \\
$\mathbf{2 0 1 1}$ & 8.908 & 17.816 \\
$\mathbf{2 0 1 2}$ & 9.470 & 17.046 \\
$\mathbf{2 0 1 3}$ & 11.000 & 24.200 \\
$\mathbf{2 0 1 4}$ & 11.000 & 24.200 \\
$\mathbf{2 0 1 5}$ & 11.000 & 24.200 \\
$\mathbf{2 0 1 6}$ & 11.000 & 24.200 \\
$\mathbf{2 0 1 7}$ & 9.500 & 26.600 \\
\hline
\end{tabular}

Como apresentado na Tabela 5, a área colhida e a produção no período compreendido entre os anos de 2007 e 2017 apresentam oscilações sazonais por se tratar de uma cultura agrícola submetida às variáveis de ordem climática (granizo, ventos, estiagens, entre outros). Além disso, a área colhida vem sofrendo alterações nos últimos anos. No ano de 2007 , foram 10.000 hectares colhidos e uma produção da ordem de 22.000 toneladas. Já em 2017, 9.500 hectares plantados resultaram 
em uma produção de 26.600 toneladas. Isso se explica em parte pela seletividade dos sistemas integrados de produção, que aumentam a quantidade produzida, ao mesmo tempo em que excluem produtores, com o consequente aumento de produtividade. Mazoyer e Roudart (2010, p. 27) abordam que:

Em pouco mais de um século, a diferença [de] produtividade da agricultura menos produtiva do mundo, praticada exclusivamente com ferramentas manuais (enxada, pá, cajado, facão, faca, ceifadeira, foice...) e a agricultura mais bem equipada e produtiva do momento, realmente se acentuou: passou de 1 contra 10 no período de entre guerras, de 1 para 2.000 no final do século XX.

Os sistemas integrados de produção são seletivos quando se tem em conta a realidade dos produtores, aqueles que não atendam aos requisitos mercadológicos são afastados ou forçados a abandonar a produção pelas imposições de mercado. Ficam envolvidos na produção apenas aqueles produtores considerados eficientes e que são confrontados com exigências cada vez maiores no que tange à qualidade do produto final.

A Tabela 6 destaca a produção de soja no município de Canguçu (2007-2017), com enfoque para a área colhida e a quantidade produzida.

Tabela 6 - Produção de soja - Área colhida e quantidade produzida (2007-2017)

\begin{tabular}{ccc}
\hline Ano & $\begin{array}{c}\text { Área Plantada } \\
\text { (hectares) }\end{array}$ & $\begin{array}{c}\text { Quantidade Produzida } \\
(\mathbf{T})\end{array}$ \\
\hline $\mathbf{2 0 0 7}$ & 15.000 & 27.000 \\
$\mathbf{2 0 0 8}$ & 10.000 & 18.000 \\
$\mathbf{2 0 0 9}$ & 10.000 & 21.000 \\
$\mathbf{2 0 1 0}$ & 15.000 & 31.500 \\
$\mathbf{2 0 1 1}$ & 15.000 & 31.500 \\
$\mathbf{2 0 1 2}$ & 15.000 & 23.400 \\
$\mathbf{2 0 1 3}$ & 20.000 & 48.000 \\
$\mathbf{2 0 1 4}$ & 32.000 & 89.600 \\
$\mathbf{2 0 1 5}$ & 34.000 & 79.560 \\
$\mathbf{2 0 1 6}$ & 36.000 & 34.560 \\
$\mathbf{2 0 1 7}$ & 37.620 & 99.317 \\
\hline
\end{tabular}

Fonte: SIDRA, Produção Agrícola Municipal (2017).

A soja é uma cultura agrícola, considerada commodity ${ }^{8}$ presente na realidade de Canguçu desde os anos de 1980, mas reduzida naquele momento a

\footnotetext{
8 Paludo et al. (2008, p. 22), conforme Carvalho (2005, p. 198), destacam que: "Commodities é mercadoria (produtos e subprodutos), de origem agrícola, pecuária, florestal e agroextrativista, que é comercializada com maior ou menor grau de beneficiamento, predominantemente pela bolsa de mercadorias e de futuros. Elas são cotadas em dólares, em função de serem produtos preferenciais
} 
produtores dispersos e em áreas restritas. Todavia, nos últimos dez anos, passa a apresentar uma ocupação de áreas cada vez maiores e uma produtividade cada vez mais elevada. Em alguns períodos específicos, as variações na produtividade estão condicionadas às intempéries (ventos, chuvas, estiagens) que podem diminuir ou aumentar a quantidade produzida. Outro fator importante a considerar está relacionado com o avanço da soja sobre áreas antes reservadas à pecuária ou produção de milho. Amin e Vergopoulos (1986, p. 51) complementam que "[...] o motor que comanda a inserção de novas terras e o crescimento da renda é a demanda do setor não agrícola, isto é, o preço de mercado".

A Figura 3 demonstra um aspecto presente no município de Canguçu em áreas ocupadas pela soja que é a presença de residências abandonadas em meio ao espaço rural.

Figura 3 - Cultivo da soja no município de Canguçu

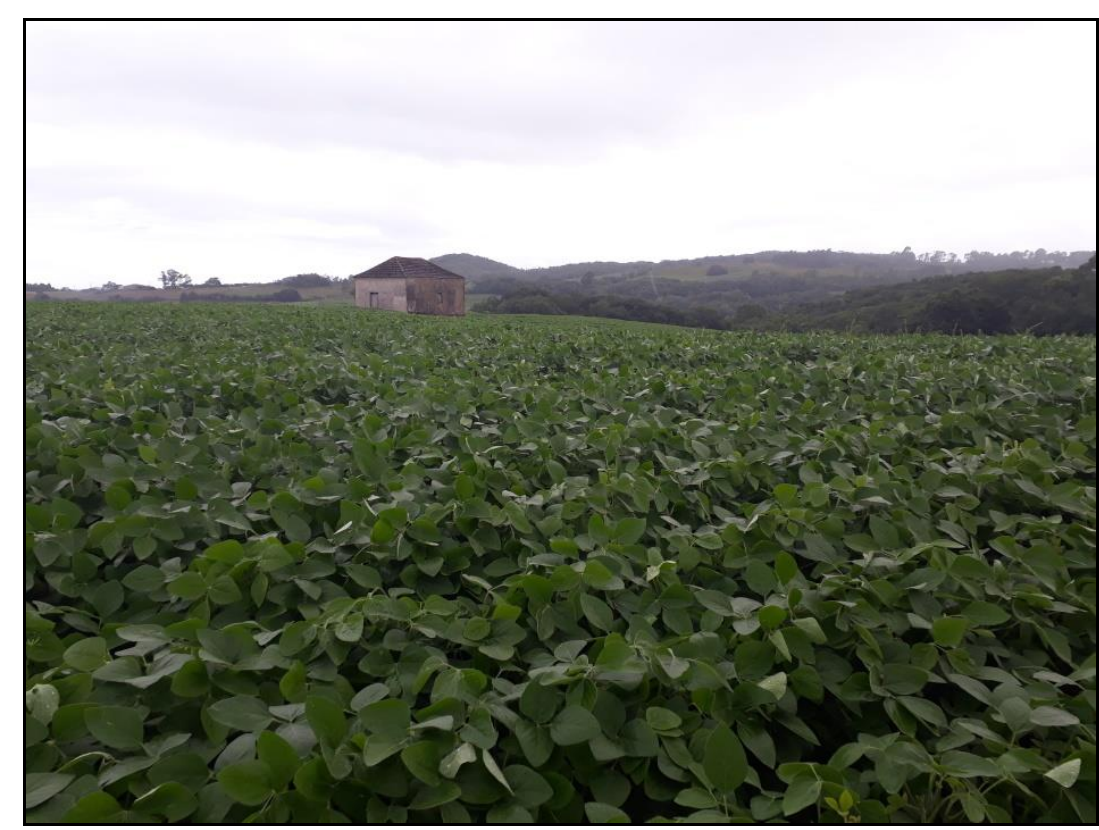

Fonte: Acervo dos autores, 2019.

As áreas utilizadas no cultivo da soja são usualmente repulsoras de mão-deobra. Um dos fatos percebidos na paisagem rural são as residências abandonadas, como um processo decorrente da modernização agrícola e sua consequência traduzida no êxodo rural. 


\section{Alternativas da agricultura familiar no contexto empírico}

Como alternativa à agricultura familiar na área de estudo, podemos mencionar a produção diversificada de alimentos cultivados de forma agroecológica, conforme pode ser observado na Figura 4. Peter (2011) aborda que a agroecologia foi inserida no município de Canguçu apoiada por três organizações não governamentais ligadas à igreja, a saber: a Pastoral do Agricultor, ligada à Igreja Anglicana; a Pastoral Rural, ligada à Igreja Católica; e o Centro de Apoio e Promoção da Agroecologia (CAPA), ligado à Igreja de Confissão Luterana no Brasil. De acordo com o mesmo autor, no final da década de 1980, essas instituições começaram a apoiar as famílias de agricultores para se reunirem coletivamente em grupos e associações com o objetivo de buscar "no trabalho coletivo a transformação da realidade social na qual estavam inseridas" (PETER, 2011, p. 19).

\section{Figura 4 - Propriedade familiar com produção agroecológica}

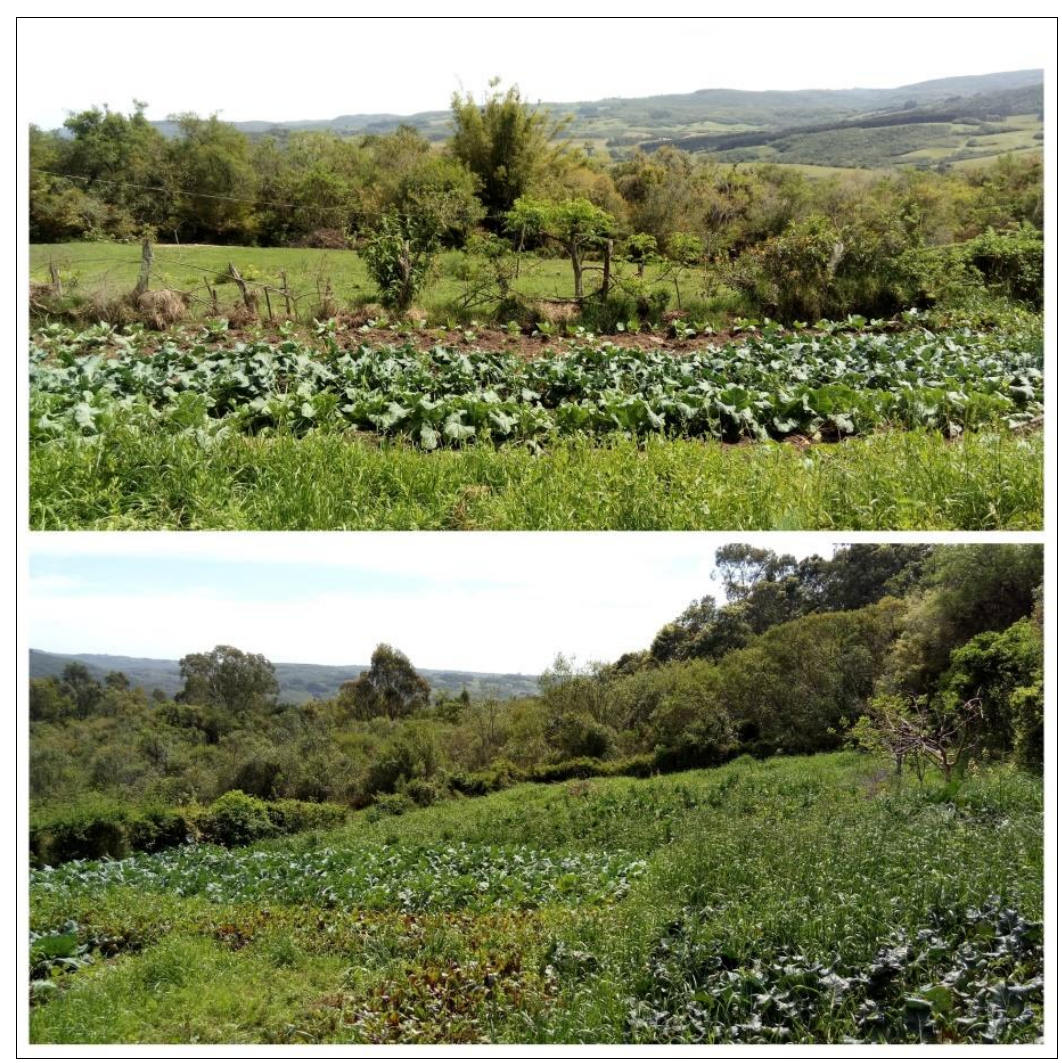

Fonte: Acervo dos autores, 2018.

Geralmente os agricultores agroecológicos estão ligados a algum grupo, associação ou cooperativa, o que proporciona uma maior facilidade quanto à 
comercialização da produção. Essa comercialização ocorre principalmente de forma direta, nas feiras da ARPA-SUL ${ }^{9}$ nos municípios de Canguçu e Pelotas, na feira da UNAIC $^{10}$ em Canguçu e por intermédio de cooperativas para o Programa de Aquisição de Alimentos (PAA) e o Programa Nacional de Alimentação Escolar (PNAE).

Observa-se, na última década, uma considerável expansão da produção agroecológica no município, e uma das causas pode ser atribuída à mudança de mentalidade dos consumidores, pois muitos estão optando por produzir, consumir e vender alimentos mais saudáveis e sem o uso de agrotóxicos. Com isso, surge uma nova demanda e possibilidade de renda para os agricultores. Cabe enfatizar a importância da instalação da Feira da ARPA-SUL no ano de 2009, a qual acontece todas as quintas-feiras em frente da Prefeitura Municipal de Canguçu, e da Feira da UNAIC, denominada Feira Sabores da Terra, inaugurada no ano de 2015 e que ocorre todas as segundas-feiras em frente da UNAIC. Estes espaços proporcionam a comercialização de produtos agroecológicos e um maior acesso desses produtos aos consumidores da área urbana do município.

Também está ocorrendo a retomada da produção de sementes crioulas no município de Canguçu e isso se dá principalmente com o apoio da UNAIC ao unir os agricultores e organizar a estrutura da cadeia produtiva das sementes crioulas. Essa produção é considerada em muitos casos como uma forma secundária ou complementar de renda para os agricultores, mas fundamental para a autonomia diante das grandes empresas sementeiras. Ressalta-se que existe a comercialização principalmente do excedente de sementes crioulas de milho e feijão por intermédio da Cooperativa União ${ }^{11}$.

\footnotetext{
${ }^{9}$ A Associação Regional de Produtores Agroecologistas da Região Sul (ARPA-SUL) foi fundada em 15 de setembro de 1995. Formada por 23 famílias provenientes dos municípios de Canguçu, Pelotas, Morro Redondo, Arroio do Padre e Turuçu. A entidade agrega agricultores familiares que trabalham exclusivamente de forma agroecológica e a produção e comercialização é feita pelos próprios agricultores (Informações extraídas do Blog Canguçu Online e atualizadas junto aos feirantes da Arpasul).

10 A União das Associações Comunitárias do Interior de Canguçu (UNAIC) foi fundada em 18 de março de 1988. Várias associações e grupos de agricultores familiares estão filiados a esta organização (Informações obtidas na página online da UNAIC).

11 A Cooperativa União vem trabalhando juntamente com a UNAIC, no resgate das sementes crioulas. Esta cooperativa está inserida nos mercados institucionais e participa de leilões e chamadas públicas das esferas do governo municipal, estadual e federal (Informações disponibilizadas material impresso e distribuído durante a 8ํㅜ Feira Estadual das Sementes Crioulas e Tecnologias Populares em Canguçu, 2017).
} 


\section{Considerações finais}

A agricultura com seus aspectos de modernização é uma realidade no município de Canguçu. É no universo da agricultura familiar que ocorre a inserção e consolidação da fumicultura e da sojicultura, que passaram a ganhar espaço em propriedades familiares. A soja geralmente está associada à produção do tabaco e é considerada uma fonte secundária de renda. Outro fato bastante comum é a parceria entre produtores familiares e produtores capitalizados através de modalidades como parceria e arrendamento. Esta imersão da agricultura familiar em culturas agrícolas como o tabaco, e em menor escala a soja, é uma das evidências do avanço capitalista em todas as esferas produtivas no campo e na cidade, como bem caracterizou Martins (1981) procurando homogeneizar os processos e as práticas produtivas.

A presença do agronegócio em municípios como Canguçu, caracterizado pela agricultura familiar, provoca ao longo do tempo alterações significativas nos aspectos de produção, na estrutura fundiária, na localização populacional e na organização do trabalho no interior das unidades familiares. A análise dos dados secundários utilizados e a realidade percebida no campo mostram a presença da atividade caracterizada como agronegócio e o contraponto a esse setor, com a diversificação, visualizando-se a produção agroecológica em outras bases produtivas.

$\mathrm{Na}$ realidade estudada, temos, como menciona Wanderley (1999), uma agricultura familiar diversa, como diversa é sua natureza. Neste contexto, além das bases produtivas tradicionais encontramos produtores de pêssego, milho, hortaliças de base orgânica e agroecológica e, ainda, produtores de sementes crioulas, vinculados à UNAIC e à Cooperativa União. A agroecologia compreende uma atividade importante para a permanência de muitas famílias do meio rural de Canguçu, incluindo a geração de emprego e renda no campo, a preservação do meio ambiente e a valorização social do agricultor.

\section{REFERÊNCIAS}

ABRAMOVAY, R. Paradigmas do capitalismo agrário em questão. São Paulo: Edusp, 2007. 
ALVES, A. F. Et al. Impactos da agroindústria integradora na agricultura familiar do sudoeste do Paraná. In: ALVES, A. F; FLÁVIO, L. C; SANTOS, R. A. Espaço e território:

interpretações e perspectivas do desenvolvimento. Francisco Beltrão: Unioeste, 2005, p. 141-167.

ALMEIDA, J. A. A construção social de uma nova agricultura. Porto Alegre: Editora da UFRGS, 2009.

ALMEIDA, M. W. B. Redescobrindo a família rural. Revista Brasileira de Ciências Sociais (RBCS), n.1, v. 11, jun. 1986, p. 66-82.

AMIM, S; VERGOPOULOS, K. A questão agrária e o capitalismo. Rio de Janeiro: Paz e Terra, 1986.

APOLINÁRIO, F. Metodologia da ciência: filosofia e prática da pesquisa. São Paulo: Pioneira Thomson Learning, 2006.

CANGUÇU ONLINE. Arpa-Sul comemora 20 anos de Feira Agroecológica. Disponível em: <https://www.cangucuonline.com.br/index.php/noticia/arpa-sul-comemora-20-anos-defeira-agroecologica>. Acesso em: 15 Nov. 2018.

CHIZZOTTI, A. Pesquisa em ciências humanas e sociais. São Paulo: Cortez, 1995. CLEPS JUNIOR, J. Questão agrária, Estado e territórios em disputa. In: Marcos, A. S; Santos, R. A. Geografia agrária, território e desenvolvimento. São Paulo: Expressão Popular, 2010, p. 35-54.

CORADINI, O. L; FREDERICQ, A. Agricultura, cooperativas e multinacionais. Rio de Janeiro: Zahar Editores, 1982.

FEATHERSTONE, M. Cultura de consumo e Pós- modernismo. São Paulo: Nobel, 1995. FELICIANO, C. A. Movimento camponês rebelde: a reforma agrária no Brasil. São Paulo: Contexto, 2006.

FERNANDES, B. M; WELCH, C. A. Campesinato e agronegócio da laranja nos EUA e Brasil. In: FERNANDES, B. M. Campesinato e agronegócio na América Latina: a questão agrária atual. São Paulo: Expressão Popular, 2008, p. 45-70.

FLACH, L. M. A integração de aves no município de Francisco Beltrão e a questão tecnológica. Geografia Econômica, n 4, Florianópolis, Julho de 2012, p. 249- 267.

FONTOURA, L. F. M. A relação cidade campo. In: Medeiros, R. M. V; Falcade, I. Tradição versus tecnologia: as novas territorialidades do espaço agrário brasileiro. Porto Alegre: Editora da UFRGS, 2009, p. 269-284.

GONÇALVES, J. S. Agronegócios: desenvolvimento e territorialidades em economias continentais. Geografia Econômica, n 4, Florianópolis, Julho de 2012, p. 57- 68.

HEYNIG, K. Principales enfoques sobre la economia campesina. Revista de la Cepal, Abril 1982, p. 117-142.

INSTITUTO BRASILEIRO DE GEOGRAFIA E ESTATÍSTICA (IBGE). Censo Demográfico 2010. Rio de Janeiro: 2010. Disponível em: <http://www.ibge.gov.br>. Acesso em: 19 ago. 2018.

INSTITUTO NACIONAL DE COLONIZAÇÃO E REFORMA AGRÁRIA (INCRA). Estrutura Fundiária (2012). Disponível em:< http://www.incra.gov.br>. Acesso em: 20 Jan. 2018.

KAUTSKY, K. A questão agrária. São Paulo: Proposta Editorial, 1980. 
LÊNIN, V. I. O desenvolvimento do capitalismo na Rússia: o processo de formação do mercado interno para a grande indústria. São Paulo: Nova Cultural, 1985.

LÓPEZ, M. La función social de la propriedade y la quimera de los agronegocios en Guatemala-Una posibilidad en el corazón de la globalización neoliberal. In: FERNANDES, B. M. Campesinato e agronegócio na América Latina: a questão agrária atual. São Paulo: Expressão Popular, 2008, p. 107-138.

MALDONADO, G; ALMEIDA, M. C; PICCIANI, A. L. Divisão territorial do trabalho e agronegócio: o papel das metrópoles nacionais e a constituição das cidades do agronegócio. In: Bernardes, J. A. Globalização do agronegócio e Land Grabbing: a atuação das megaempresas argentinas no Brasil. Rio de Janeiro: Lamparina, 2017, p. 81 96.

MARTINS, J. S. Os camponeses e a política no Brasil: as lutas sociais no campo e seu lugar no processo político. Petrópolis: Vozes, 1981.

MAZOYER, M; ROUDART, L. Histórias das agriculturas no mundo: do neolítico à crise contemporânea. São Paulo: Editora da Unesp, Brasília: NEAD, 2010.

MULLER, G. complexo agroindustrial e modernização agrária. São Paulo: HUCITEC, EDUC, 1989.

OLIVEIRA, A. U. Modo capitalista de produção e agricultura. São Paulo: Ática, 1986.

PALUDO, C. et al. A via campesina e o desenvolvimento do campo. In: Paludo, C; THIES, V. F. Desenvolvimento do campo em construção. ljuí, Ronda Alta: Editora da Unijuí, Fundep, 2008, p. 13-46.

PETER, D. S. Agroecologia como prática de organização social na agricultura familiar: o caso do grupo agroecológico do Remanso - Canguçu (RS). Trabalho de Conclusão de Curso - Planejamento e Gestão para o Desenvolvimento Rural, Universidade Federal do Rio Grande do Sul, 2011.

RESENDE, P. E. A. A federação como alternativa democrática nas relações entre as nações. In: DOWBOR, L; IANNI, O; RESENDE, P. E. A. Desafios da globalização. Petrópolis: Vozes, 1997, p. 28-42.

RODRIGUES, R. M. Pesquisa acadêmica: como facilitar o processo de preparação de suas etapas. São Paulo: Atlas, 2007.

SACCO DOS ANJOS, F; CALDAS, N. V. A horta agonizante: mercantilização da agricultura e transformações nas práticas de autoconsumo entre famílias rurais do extremo sul gaúcho.

Revista Pensamento Plural, v. 5, p. 151-169, jul/dez, 2009.

SCHNEIDER, S. et al. Histórico, caracterização e dinâmica recente do Pronaf- Programa Nacional de Fortalecimento da Agricultura Familiar. In: SCHNEIDER, S; SILVA, M. K; MARQUES, P. E. M. (Orgs). Políticas públicas e participação social no Brasil rural. Porto Alegre: Editora da UFRGS, 2004, p. 21-50.

SCHNEIDER, S. Teoria social, agricultura familiar e pluriatividade. Revista Brasileira de Ciências Sociais (impresso), São Paulo. v. 18, n.151, p. 99-121, 2003.

SISTEMA IBGE DE RECUPERAÇÃO AUTOMÁTICA (SIDRA). Produção Agrícola Municipal. Disponível em:<https://sidra.ibge.gov.br>. Acesso em: 23 Nov. 2018.

SILVA, J. G. Tecnologia e agricultura familiar. Porto Alegre: Ed. UFRGS, 1999. 
SINDICATO INTERESTADUAL DA INDÚSTRIA DO TABACO (SINDITABACO). Disponível em: <http:www.sinditabaco.com.br>. Acesso em: 12 Nov. 2018.

SUZUKI, J. C. Modernização, território e relação campo-cidade: uma outra leitura da modernização da agricultura. In: Medeiros, R. M. V; FALCADE, I. (Orgs.). Tradição versus tecnologia: as novas territorialidades do espaço agrário brasileiro. Porto Alegre: Ed. UFRGS, 2009, p. 241-253.

UNAIC, União das Associações Comunitárias do Interior de Canguçu. Quem somos. Disponível em: <http://unaic.blogspot.com>. Acesso em: 25 Out. 2018.

WANDERLEY, M. N. B. Raízes do campesinato. In: TEDESCO, J. C. Agricultura familiar: Realidades e perspectivas. Passo Fundo: EDUPF, 1999, p. 23-56.

\section{NOTAS DE AUTOR}

\section{CONTRIBUIÇÃO DE AUTORIA}

Jussara Mantelli - Concepção, Análise de dados, Elaboração do manuscrito.

Éder Jardel da Silva Dutra - Concepção. Coleta de dados, Análise de dados, Elaboração do manuscrito. Queli Rejane da Silva Konzgen - Concepção, Coleta e análise de dados, Elaboração do manuscrito.

\section{FINANCIAMENTO}

Não se aplica.

\section{CONSENTIMENTO DE USO DE IMAGEM}

Não se aplica.

\section{APROVAÇÃO DE COMITÊ DE ÉTICA EM PESQUISA}

Não se aplica.

\section{CONFLITO DE INTERESSES}

Não se aplica

\section{LICENÇA DE USO}

Este artigo está licenciado sob a Licença Creative Commons CC-BY. Com essa licença você pode compartilhar, adaptar, criar para qualquer fim, desde que atribua a autoria da obra.

\section{HISTÓRICO}

Recebido em: 22-01-2019

Aprovado em: 24-02-2019 